\title{
AVALIAÇÃO PATRIMONIAL EM CONTABILIDADE Á VALORES DE ENTRADA E SAÍDA
}

\author{
João Eduardo Prudêncio Tinoco \\ Mestre e Doutorando pelo Departamento e Atuária da FEA/USP.
}

\section{APRESENTACÃ̃O}

Dúvida não padece que o tema tratado neste artigo, a Avaliação a Valores de Entrada e de Saída, é um assunto extremamente controvertido entre os teóricos da Contabilidade.

Nos últimos anos várias correntes de pensamento têm externado suas posições ante o problema inflacionário que assola os países capitalistas ocidentais, contribuindo para o debate. Essas contribuições buscam soluções teóricas que minimizem os efeitos das variações de preços nos demonstrativos contábeis de forma a possibilitar informações mais amplas, úteis, objetivas e transparentes para os usuários da informação contábil.

O objetivo deste artigo visa apresentar os diversos pesquisadores que têm contribuído para a evolução da Teoria Contábil, especialmente no que concerne à Avaliação a Valores de Entrada e de Saída, bem como uma resenha do estado da arte em que se encontram as diversas abordagens de avaliação que conformam a Contabilidade.

\section{1- AVALIACÃO PATRIMONIAL EM CONTABILIDADE A VALORES DE ENTRADA E DE SAÍDA}

\subsection{Painel Evolutivo da Contabilidade, na Avaliação a Valores de Entrada e de Saída}

A Contabilidade, desde seus primórdios, tem procurado adaptar-se a evolução do desenvolvimento das organizações e dos negócios, ainda que muitas vezes essa evolução a nosso juízo não ocorra com a velocidade que as atividades econômicas requerem.

Um dos muitos aspectos que poderíamos realçar da Contabilidade diz respeito ao seu caráter utilitário. A Contabilidade é, como sabemos, uma ciência utilitária.Segundo ludicibus (1981):

\footnotetext{
"A Contabilidade é uma ciência essencialmente utilitária, no sentido de que responde, por mecanismos próprios, e estímulos informativos dos vários setores da Economia".

Portanto, entender a evolução das sociedades, em seus aspectos econômicos, dos usuários da informação contábil, em suas necessidades da informação contábil, suas necessidades informativas, é a melhor forma de entender e definir os objetivos da Contabilidade ".
}

Há consenso quanto à informação que hoje é fornecida pela Contabilidade?

O que pretendem os usuários da informação contábil?

$\mathrm{Na}$ tentativa de responder a essas questões, especificamente no que tange à Avaliação a Valores de Entrada e de Saída, diríamos que o problema de avaliação em Contabilidade não é um problema novo, como também não o é o problema da inflação específica e geral e sua influência na mensuração do resultado das empresas.

Caderno de Estudos no06, São Paulo, FIPECAFI, Outubro/1992 
Ao longo do tempo várias teorias têm sido formuladas, especialmente a partir de 1920 (época da hiperinflação alemã), no que concerne às flutuações de preços e seus impactos na mensuração do resultado das empresas. No intuito de evidenciar a contribuição dos principais formuladores dessas teorias, no tempo e no espaço, é nossa intenção fazer uma explicitação, ainda que resumida, dos principais autores que contribuíram para o desenvolvimento da Avaliação em Contabilidade. Essa apresentação seque a ordem cronológica em que os trabalhos foram publicados.

\section{2 - Principais Pesquisadores na Avaliação Patrimonial}

Nesta seção colocaremos em destaque os autores e as datas em que seus trabalhos foram publicados, especialmente daqueles que mais contribuíram para a edificação do alicerce da teoria. Não é nossa preocupação discutir aqui a corrente de pensamento a que cada autor se filia, nem polemizar. Simplesmente iremos apresentar os autores. Nossas pesquisas compreendem os trabalhos realizados durante este século e valeram-se de fontes primárias e de citações de outros autores.

\section{THEODORE LIMPERG}

Este autor de origem holandesa, que era um Contador Público e Professor da Universidade de Amsterdã, desenvolveu entre 1912-1918 um sistema de contabilidade conhecido como: "Replacement Value Theory", Segundo Mest (1982), várias grandes empresas holandesas adotam a metodologia da Replacement Value Theory, destacando-se entre estas a N. V. Philips Industries, que usa este sistema desde 1951, tanto para fins internos como para externos. Limperg expunha que para tomar decisões racionais o gestor deveria conhecer a qualquer tempo o valor de que estava sendo produzido e quanto custaria à reposição dos bens e serviços que estavam sendo vendidos. Para isso deveria possuir um eficiente sistema de contabilidade que privilegiasse a mensuração dos resultados sob o ponto de vista da manutenção do capital físico.

Uma outra consideração importante subjacente ao desenvolvimento da teoria é a de que esta levava em consideração o desenvolvimento tecnológico que eventualmente afetasse os valores dos ativos e, por conseguinte, dos resultados das organizações.

\section{W. A. PATON}

Logo no inicio de 1918 este autor, junto com STEVENSON, publicou o livro 'Principles of Accounting", onde segundo Sweeney (1964), foram os primeiros proeminentes autores de Contabilidade a terem uma visão de abandonar, segundo certas condições, a dependência absoluta ao princípio de custo original como base de valor em contabilidade. Em 1920 Paton novamente explicou sua criatividade apresentando o artigo "Depreciation, Appreciation and Produtive Capacity", publicado no Journal of Accountancy, em que questiona o custo histórico como base de valor ideal para a Contabilidade.

\section{MIDDLEDITCH}

Este autor também foi um dos pioneiros da "Price-Level Accounting", tendo em 1918 publicado no Journal Accountancy um artigo provocante intitulado "Should Accounts Reflect the Changing Value of the Dolar?"

\section{FRITZ SCHMIDT E EUGEN SCHAMALENBACH}

Estes dois pesquisadores alemães pesquisaram e publicaram obras independentes, Caderno de Estudos no06, São Paulo, FIPECAFI, Outubro/1992 
porém foram contemporâneos. Vivenciaram a hiperinflação alemã de 1920, na qual se influenciaram para pesquisar os efeitos nefastos que a inflação impunha às empresas e às pessoas em geral. Segundo Most (1982), Schmidt examinou várias possibilidades de contabilização sob inflação, na década de 20, entre elas a de contabilização em moeda constante. A obra de Schmidt está explicitada em diversos artigos e no livro "Die Organische Tageswertbilanz", o qual também contém uma bibliografia de trabalhos de outros autores alemães. Para muitos pesquisadores é considerado o pioneiro dos pioneiros na Teoria do "Price-Level". Sua obra influenciou sobremaneira Sweeney, que a partir da formulação intelectual de Schmidt, deu um tratamento mais amplo e sistematizado relacionado aos impactos da inflação nos demonstrativos contábeis.

Scmalenbach publicou originalmente em 1916 a obra "Dynamisch Bilanz", que teve várias edições. Em edição publicada nos anos 20, observando os aspectos negativos da inflação sobre o desempenho das empresas, assim se expressou:

"Durante inflação, os administradores tentam inicialmente minimizar saldo em caixa, tomar emprestado o máximo possível, forçam os devedores a pagar rapidamente, e usar os excessos de capital de giro na compra de mercadorias, equipamentos, moedas (divisas) de outros países, ou outros tipos de proteção".

Na edição francesa de 1961, Schmalenbach assim se expressa:

"A medida que a inflação alemã aumentava, o marco deteriorava-se e os contratos de compra e venda foram liberados em divisas ou em função de índices de preços do dia. Fazia-se então necessário uma contabilização em moeda indexada:

aparecia assim uma diversidade de bases de transações, imagens sobretudo aflitivas, que variavam em função da depreciação monetária".

\section{H. W. SWEENEY}

Autor norte-americano, que pesquisou e escreveu sobre os problemas da inflação e de seu impacto na Contabilidade durante os anos 20 e 30 deste século. Reviu a literatura de Contabilidade sob inflação, originária da Alemanha dos anos 20 , notadamente o trabalho de Fritz Schmidt e examinou varias possibilidades nas quais a contabilidade em dólares de poder aquisitivo constante era uma delas. Foi um dos pioneiros na abordagem dos problemas da Avaliação em Contabilidade, sobretudo na elaboração da teoria de "ajustamentos do Custo Histórico pelos Índices de Variação do poder aquisitivo da Moeda" . Seu trabalho "Stabilized Accounting" Foi publicado originalmente em 1936. Todavia, desde 1927 o autor já vinha apresentando trabalhos de relevo, destacando-se entre estes: "Effects of Inflation on German Accountting"; "German Inflation Accounting", publicados no "Journal os Accountancy" em março de 1927 e fevereiro de 1928.

Publicou também entre outros artigos os seguintes: "How Inflation Affects BalanceSheets" e "The Technique of Stabilized Accounting", pela Accounting Review em dezembro de 1934 e em junho de 1935. Influenciou sobremaneira muitos pesquisadores pelo mundo afora no desenvolvimento da teoria contábil.

No livro "Stabilized Accounting", sua principal obra, querendo chamar a atenção para os aspectos nefastos da avaliação em contabilidade sob inflação, numa passagem a nosso prejuízo brilhante assim se expressou:

"O sucesso de todo o sistema de negócios depende da confiabilidade dos relatórios de informação. Estes por sua vez dependem principalmente da exatidão da Contabilidade. E a confiabilidade da Contabilidade depende amplamente da veracidade do dólar e o dólar é uma mentira! Pois diz uma coisa e significa outra".

Caderno de Estudos n06, São Paulo, FIPECAFI, Outubro/1992 


\section{KENNETH MAC NEAL}

Publicou em 1939 pela Scholars Book Co. o livro "Truth in Accounting" Segundo Vernon Kam (1986) , na época em que publicou o livro Mac Neal não foi levado muito a sério pela profissão contábil. Entretanto, foi um dos precursores da corrente de pensamento da Contabilidade a Valores de Saída. Entre outras considerações sugeria que os ativos negociáveis deveriam ser avaliados a valores de saída, enquanto que os ativos permanentes deveriam ser avaliados a custo de reposição, e os ativos ocasionais não negociáveis e não reproduzíveis a custo histórico. O Demonstrativo de Resultados deveriam incluir lucros e perdas realizados ou não.

\section{ELDON S. HENDRIKSEN}

Também pode ser considerado um dos pioneiros no desenvolvimento da Teoria de "PriceLevel". Nos anos 50 o autor desenvolveu vários trabalhos de pesquisa, merecendo referência o estudo de caso que realizou sobre duas firmas de utilidade pública: "Price-Level - Ajustments of Financial Statements - An Evaluation and Case Study of two Public Utility Firms", publicado por Pulman Washington State University Press, 1961.

O autor publicou em 1970 um dos livros que se constitui num dos pilares para o estudo da Contabilidade, denominado "Accounting Theory", que contribuiu para disseminar entre outros temas os diversos conceitos de avaliação, bem como os autores que a empreenderam.

\section{RAYMOND J. CHAMBERS}

É o principal expoente da Avaliação a Valores de Saída. Pesquisador notável, australiano de nascimento, durante muitos anos dedica-se à docência e à pesquisa da Contabilidade na Universidade de Sidney, na Austrália. Durante os anos 50 e até meados de 60 realiza estudos sob o efeito da inflação nos demonstrativos contábeis, mantendo, todavia preferência pela Contabilidade a Custo Corrente. Entretanto, em 1965 publica "Measurement in Accounting", passando a considerar "Resale Values" - valores de saída -como a melhor forma de avaliação em Contabilidade. Esta sua posição é reafirmada em 1966 no livro "Accountting Evaluation and Economic Behavior".

\section{EDGAR O. EDWARDS e PHILIP W. BELL}

Estes autores, dois americanos, escreveram em 1961 uma das obras capitais para o desenvolvimento da Contabilidade, intitulada "The Theory and Measurement of Business Income". A obra sintetiza toda a teoria desenvolvida até o momento quanto às flutuações de preços, do mencionado "General Price Level", porém apresenta de forma completa a "Teoria de Custo Corrente", procurando mostrar e justificar teoricamente a adoção do Custo Corrente como base de valor ideal para a contabilidade.

A obra revolucionou por completo a Contabilidade, fez muitos seguidores pelo mundo afora, sendo aceita junto à maior parte da comunidade acadêmica (que professa a avaliação em contabilidade a valores de entrada) que divulgou esta obra. Mesmo enfrentando o conservadorisino que ainda domina a classe e os órgãos contábeis, alguns países já adotam/adotaram seus conceitos, principalmente para fins contábeis, e societários.

\section{SÉRGIO DE IUDÍCIBUS}

O professor ludícibus é um dos pioneiros da Escola Brasileira de Contabilidade, no que tange a Teoria dos ajustamentos Contábeis sob a inflação.

Caderno de Estudos nº6, São Paulo, FIPECAFI, Outubro/1992 
Seu trabalho pioneiro em 1966, com o qual obteve o titulo de Doutor na USP "Contribuição à Teoria dos Ajustamentos Contábeis" constitui-se no marco inicial da escola que continua florescendo.

A obra dos professores americanos Edwards e Bell, já mencionada, bem como, entre outros de R. Matessich, Hendriksen e Joel Dean influenciaram o trabalho do autor. Neste trabalho, além de apresentar a contribuição daqueles pesquisadores, especialmente Edwards e Bell, apresentam seu conceito de "Custo Corrente Puro", que inova em relação a estes.

Em 1968, continuando seus trabalhos de pesquisa e docência no Departamento de Contabilidade e Atuária da USP, publica o trabalho "Aspectos da Avaliação de Estoques a Preços Correntes", aplicado a uma empresa industrial, com o qual obteve o título de Livre-Docente.

\section{ALKINDAR RAMOS DE TOLEDO}

Juntamente com ludicibus é um dos pioneiros da Escola Brasileira de Contabilidade. Seu trabalho original foi apresentado em 1968 e intitula-se "O Problema da Amortização dos Bens Depreciáveis e as Necessidades Administrativas das Empresas". Nesta obra estudou profundamente o problema da depreciação, fazendo sua ligação com a "Teoria do Custo Histórico Corrigido", onde menciona Sweeney, como um dos seus principais inspiradores, e com a "Teoria do Custo Corrente", onde se influencia em Edwards e Bell, porém explicita o modelo apresentado por ludicibus, que é derivado daquele.

\section{ELISEU MARTINS}

O autor, discípulo de ludicibus e Alkindar, é também um dos pioneiros do estudo dos problemas inflacionários e da avaliação na contabilidade brasileira.

Dentre suas obras mais importantes destacam-se:

"Contribuição à Avaliação do Ativo Intangível" e "Análise da Correção Monetária das Demonstrações Financeiras".

Na primeira obra estuda pioneiramente a Avaliação do "Goodwill", na Contabilidade no Brasil, mostrando com riqueza de detalhes a ligação da Contabilidade com a Economia. Na segunda apresenta um conceito, que a nosso juízo revoluciona por completo o estudo das Finanças das empresas, ao estudar a Alavancagem (leverage) Financeira, sob o contexto inflacionário. Ou seja, introduz a inflação nos estudos da alavancagem, mostrando como este conceito melhora em termos preditivos para os usuários da informação contábil e financeira.

\section{NATAN SZUSTER}

Discípulo dos Professores ludicibus e Martins, apresentou em 1985 ao Departamento de Contabilidade e Atuária da USP sua tese de Doutoramento "Análise do Lucro Passível de Distribuição: Uma Abordagem Reconhecendo a Manutenção do Capital da Empresa".

Este trabalho inova alguns aspectos a obra pioneira de Edwards e Bell, superando-a especialmente no que concerne à distribuição de lucro com a Manutenção Simultânea do Capital Físico e do Capital Monetário. Demonstrou nesse trabalho a impossibilidade de se distribuir a totalidade do lucro apurado de acordo com o método do "Custo Corrente Corrigido", sob pena de se contrair a capacidade produtiva, ou seja, de geração de receitas de uma empresa.

\section{OUTROS AUTORES}

Face ao aspecto limitado deixamos de mencionar autores que também contribuíram para o avanço do estudo da avaliação patrimonial em contabilidade. Entre estes merecem referência: 
Largay e Livingstone que publicaram o livro "Accounting for Changing Prices" por John Wiley \& Sons mc. 1976; e STERLING R. ROBERT, "Asset Valuation and Income Determination”, Scholars Book Co., 1971.

\title{
2-- ABORDAGEM CONCEITUAL E CONFRONTO DE TEORIA
}

Preliminarmente devemos mencionar que os principais autores que advogam (advogaram) a Avaliação a Valores de Entrada são: Edwards e Bell, Sweeney e Hendriksen.

Quanto àqueles que opinaram pela preponderância (e que são em número muito menor) da Avaliação a Valores de Saída destacam-se: Chambers, Sterling e Kenneth Mac Neal.

Os Valores de entrada representam os obtidos no mercado de compra de uma entidade, ou então, refletem o custo ou sacrifício para obter os ativos utilizados pela empresa em suas operações.

Os Valores de Saída representam, segundo Martins (1972), "aqueles obtidos no mercado de venda". Edwards e Bell especificam que Valores de Saída podem ser distribuídos nos seguintes grupos (1961): Valores Esperados; Valores Correntes e Custo de Oportunidade.

Os teóricos da contabilidade, no estágio em que se encontra o desenvolvimento da Teoria Contábil, apresentam as principais alternativas baseadas em Valores de Entrada e de Saída e que são:

\section{Valores de Entrada}

\author{
Custo Histórico \\ Custo Corrente \\ Custo Histórico Corrigido \\ Custo Corrente Corrigido
}

\section{Valores de Saída}

- $\quad$ Preços Correntes de Saída ou Valor Realizável Liquido

- $\quad$ Valores de Liquidação

- $\quad$ Equivalentes Correntes de Caixa

- $\quad$ Fluxo da Caixa Descontado

Na próxima seção faremos uma abordagem teórica, resumida, das diversas alternativas de avaliação a valores de entrada e de saída. Antes de expormos conceitualmente o que cada abordagem especifica, faz-se necessário explicitar que o fim em si da informação contábil é o usuário. As diversas alternativas procuram cada uma de por si evidenciar a informação que melhor atenda o modelo preditivo de cada usuário.

Deve-se também mencionar que a avaliação patrimonial conforme procedida pela Contabilidade independe da existência da inflação. Oportunamente nas considerações finais deste artigo aprofundaremos essas considerações.

\section{$\underline{2.1}$ - Avaliação a Valores de Entrada}

\subsubsection{Custo Histórico}

Poderíamos resumi-lo como sendo um conceito de avaliação estático que não leva em consideração o caráter dinâmico da economia com suas invariáveis trocas de preços.

Caderno de Estudos n06, São Paulo, FIPECAFI, Outubro/1992 
Porém, ainda é o conceito de avaliação mais comum em Contabilidade e presumido constantemente como sendo o mesmo um sinônimo da avaliação contábil.

Martins (1972) denomina-o como "aquele que representa o valor pelo qual um elemento do ativo foi adquirido, ou construído, sem que nenhuma atenção seja dada à variação da capacidade aquisitiva da moeda entre a data de aquisição e outra qualquer. Também não considera a variação do preço específico dos ativos estocados". Sob esta ótica o lucro tem origem pela diferença observada entre as receitas e as despesas, não levando em conta a época de formação. Demonstrativos baseados em custos históricos não são relevantes para a tomada de decisões quando existem flutuações gerais ou específicas de preços, ainda que revele uma pretensa aderência no momento da aquisição dos ativos para expressar os potenciais serviços futuros.

\subsection{2- Custo Corrente}

Esta metodologia de avaliação pode ser compreendida segundo duas óticas: a contábil e a econômica. Sob a ótica contábil o lucro é reflexo de eventos passados, enquanto que sob a econômica é o reflexo da comparação entre eventos ainda por ocorrer.

O Custo Corrente, segundo Edwards e Bell (1961), são definidos como "o custo corrente de aquisição dos inputs que a firma utilizou para produzir o elemento do ativo". Martins (1972) aceita esta definição mas propõe a substituição de verbo produzir pelo verbo possuir, sob a alegação de "a soma de inputs nos leva a situação de diferenciarmos a: a) quando a empresa fabricou o ativo, o seu custo corrente é a soma dos custos correntes dos fatores que entraram na sua produção; b) quando a empresa comprou o ativo é o custo corrente de adquirí-lo"."

Em períodos de acentuadas flutuações de preços, a entidade obtém lucros quer em forma de aquisição antecipada de bens (formação de estoques), quer por outros eventos de caráter especulativo. Tais lucros, porém, somente são reconhecidos pela contabilidade ortodoxa quando efetivamente realizados, ou seja, quando grande parte do esforço para obter a receita foi desenvolvido, quando existe um valor objetivo e é possível delinear os custos e ou despesas correspondentes.

Ainda que sujeito a pequenas críticas, o custo corrente traz no seu bojo grandes vantagens para quem o utiliza, entre as quais pode cita-se: 1) representa a melhor medida de valor das entradas comparadas com as receitas correntes em termos atuais; 2) possibilita a identificação de ganhos ou perdas pela manutenção de ativos; 3 ) estima os valores correntes dos inventários no final do período se a firma ainda estiver adquirindo tais insumos, caso não forem aplicáveis os valores realizáveis líquidos; 4) a somatória dos ativos expressos em termos correntes é mais significativa do que os custos históricos incorridos em diferentes períodos de tempo; 5) para o usuário e investidor externo pode-se aproximar razoavelmente, com ajustes, do valor que deveria pagar para montar uma fábrica igual (em estado de nova) àquela que se está avaliando; 6) como o custo corrente representa hoje uma medida de valor de compra dos ativos, quando amortizamos esses ativos para despesa temos uma comparação mais adequada entre valores correntes de receitas e de despesas.

\subsubsection{Custo Histórico Corrigido}

Esta teoria, cuja denominação original é "Price-Level. Accountiflg", preocupa-se exclusivamente com a restauração dos custos históricos.

Sua metodologia prevê o restabelecimento dos custos incorridos em operações anteriores em termos de um poder aquisitivo da moeda de uma data determinada, ou em outras palavras: abre a possibilidade de se colocar diversos custos de datas diferentes em termos de uma moeda de capacidade aquisitiva (geral ou especifica), de uma outra data qualquer.

Não traz, nem tampouco introduz, nenhum conceito inovador em relação à Contabilidade tradicional, a exemplo do que fazem o custo corrente e o custo corrente corrigido. Dessa maneira as economias de custos realizadas e os ganhos de capital não realizados, que revelam de forma antecipada o ganho ou perda pela manutenção de ativos, não aparece em sua demonstração,

Caderno de Estudos n06, São Paulo, FIPECAFI, Outubro/1992 
retirando um grande instrumento para a tomada de decisão. Difere, com relação à contabilidade a custos históricos, pela apuração dos ganhos ou perdas com os itens monetários, igualmente presentes no custo corrente corrigidos.

Por esta teoria o lucro é definido pela diferença entre as receitas e as despesas (com base em suas datas de formação), mais um acréscimo ou decréscimo de ganho ou perda com os itens monetários. Pelo que pode ser observado não reconhece a existência de outros lucros ou prejuízos, que não os já realizados, o que de certa forma enfraquece o seu poder preditivo para os usuários da informação contábil.

Evidentemente, suas vantagens sobre o custo histórico são inegáveis pois sua simplicidade leva de imediato a uma avaliação do patrimônio líquido, tornando evidente o patrimônio a ser mantido para efeito de distribuição de lucros.

\subsubsection{Custo Corrente Corrigido}

Poder-se-ia definir o Custo Corrente Corrigido como uma extensão do Custo Corrente, só que sujeito a um ajustamento em função de um Índice Geral de Preços.

Para alguns pesquisadores é talvez o mais completo conceito de avaliação a valores de entrada, pois combina as vantagens do custo corrente com as do custo histórico corrigido.

Segundo Martins (1972) "é muito mais apropriado e realístico, pois ao comparar os custos correntes de um mesmo ativo entre duas datas ou ao comparar seu custo corrente com o histórico, leva em conta a parte dessa diferença que é fictícia devido à variação da capacidade aquisitiva da moeda". Parte da premissa que mesmo levando-se em consideração que em datas especificas os ativos representam uma boa aproximação dos seus valores econômicos, estes não podem ser comparáveis nas duas datas, se neste período tiver ocorrido uma variação no poder aquisitivo da moeda. Propõe para a solução deste problema levar os ativos a uma mesma moeda (chamada moeda de fim), tomando seus valores correntes e multiplicando-os pelo coeficiente de variação geral de preços. Com ambos os ativos em moeda da mesma data é possível a comparação.

Nesta teoria o lucro é definido pela diferença entre as receitas e as despesas (corrigidas pelas suas datas de formação), levando-se em consideração as perdas ou ganhos com a inflação e o acréscimo ou decréscimo relativo à diferença entre os ativos mantidos a custo corrente e a custo histórico (ambos corrigidos).

Ao comparar-se o custo corrente e o custo corrente corrigido verifica-se o surgimento de um novo elemento denominado ganho ou perdas nos itens monetários, que nada mais é do que a tentativa de reconhecer o efeito inflacionário sobre as dividas e créditos da empresa no período. Os demais elementos e contas permanecem com a mesma denominação adotada pelo custo corrente.

Por conseguir captar a variação específica dos preços, juntamente com a variação geral, o custo corrente corrigido é considerado como o mais completo conceito de avaliação de ativos a valores de entrada.

\section{2 - Avaliação a Valores de Saída}

\subsection{1 - Preços Correntes de Saída ou Valor Realizável Líquido}

A Avaliação a Valores de Saída parte de uma premissa básica que é o valor pelo qual os ativos podem ser vendidos ou trocados quando deixarem a empresa, ou seja, baseia-se no preço de troca correspondente ao produto ou produção da empresa.

Segundo essa metodologia, quando a empresa opera em um mercado organizado o preço vigente de mercado pode ser considerado uma estimativa bem próxima do preço real de venda em um curto prazo. O Valor Realizável Líquido é obtido, na maioria das vezes, a partir do preço de venda cotado sobre a demanda do mercado.

A maioria dos autores de Contabilidade apresenta vários problemas na avaliação

Caderno de Estudos no06, São Paulo, FIPECAFI, Outubro/1992 
preconizada por esta abordagem. Assim, para muitos não pode ser utilizado como conceito geral de avaliação de ativo, pois somente se aplica a ativos destinados a venda, como produtos acabados. Como o valor realizável liquido é um substituto de um preço de venda futuro, a efetiva conversão em termos de entrada de caixa sempre será exposta a dúvidas. Por outro lado, o preço corrente de venda significa a importância que está sendo paga pelo comprador marginal no momento, não sendo portanto possível extrapolar condições idênticas para o futuro, salvo em condições idênticas ("ceteris paribus"). Estas e outras dificuldades são apontadas para esta metodologia. Porém esta abordagem também apresenta algumas vantagens, que podem ser destacadas:

1) quando a empresa atua num mercado organizado e pode calcular com previsão os custos adicionais de venda, a avaliação a preços de saída proporciona informações relevantes e constante atualizadas;

2) considerações do custo de oportunidade como o valor de caixa derivado da venda de um ativo ou do valor presente dos benefícios derivados do uso de um ativo.

Para efeito de apuração do lucro quando utilizada esta abordagem, reconhece-se um lucro futuro, relativo ao preço de venda, partindo-se da premissa que o preço atual seja um bom substituto do preço de saída.

\subsection{2 - Valores de liquidação}

Esta é uma abordagem que implica na descontinuidade de uma entidade. Pode ser considerada como a mais extrema da hipótese de avaliação a valores de saída.

Por não serem realistas em circunstâncias normais, os valores de liquidação devem ser utilizados em situações específicas, como:

1) quando os produtos e outros ativos tenham perdido sua utilidade normal, ficando obsoletos ou por outro motivo qualquer tenham perdido o seu mercado normal;

2) quando a empresa espera desativar seus negócios em um futuro próximo, de modo que não poderá vender em seu mercado normal.

\subsection{3 - Equivalentes Correspondentes de Caixa}

Metodologia sugerida por Chambers, que traz no seu bojo o postulado da continuidade.

Chambers (1965) explicita que "uma empresa em continuidade adapta-se sucessivamente pela venda de seus ativos no curso normal de seu negócio, isto é, adota um conceito de liquidação ordenada, em vez de liquidação forçada". Sob este aspecto toda entidade tem um horizonte de vida definido (ceteris paribus) e logicamente quanto mais ordenada for a liquidação dos ativos, menores serão os prejuízos na fase de liquidação forçada ou de obsolescência do empreendimento.

Apoiado em sua colocação Chambers propõe como conceito de avaliação único para todos os ativos o que denominou "Equivalentes Correntes de Caixa", cuja base de argumentação para utilização foi defendida desta forma: "certamente bens e serviços são somente adquiridos porque possuem características físicas ou tangíveis que se acreditam serem capazes de atender ou serem úteis às suas finalidades. As trocas no mercado não apresentam necessariamente uma ligação entre preço e grau de utilidade, já que os preços são determinados pelas utilidades que proporcionam, mas através da interação entre a procura e a oferta. Todos os cálculos em unidades monetárias são em termos de preço: como eles foram no passado, como são no presente e como serão esperados no futuro. O objetivo do cálculo é obter convicção no qual uma conduta futura possa ser baseada, e esses cálculos não podem ter quaisquer relações com eventos passados".

Possui como inconveniente para efeito de avaliação de ativos como um todo o fato de alguns ativos intangíveis e até mesmo tangíveis não encontrarem no mercado o seu

Caderno de Estudos n06, São Paulo, FIPECAFI, Outubro/1992 
Avaliação Patrimonial em Contabilidade á Valores de Entrada e Saída 10

correspondente especifico.

\subsection{4 - Fluxo de Caixa Descontado}

O valor de um ativo é o equivalente monetário de seus serviços potenciais. Conceitualmente este é a soma dos preços futuros de mercado de todos os fluxos de serviços que se obterão, descontados por fatores de probabilidades e juros a seus valores atuais.

Este conceito de avaliação exige o prévio conhecimento de três variáveis básicas que devem ser determinadas para sua adoção:

1) a importância (caso recebida em uma única vez) ou as importâncias (caso recebidas em períodos distintos) que serão recebidas;

2) o fator de desconto (taxa de juros) ;

3) o período ou períodos compreendidos.

\section{III - PROBLEMAS INFLACIONÁRIOS NA CONTABILIDADE}

Desde seus primórdios os "princípios contábeis geralmente aceitos", partiram da premissa de preços plenamente estáveis na economia.

Todavia, essas premissas ao longo do século XX têm se mostrado falhas, haja vista que várias hiper-inflações já ocorreram em vários países. Só a Alemanha teve duas: entre 1920 e 1923 e logo após a Segunda Guerra Mundial. Hungria, Polônia, Israel e Checoslováquia também experimentaram (não esquecendo da Áustria) hiper-inflações. A Argentina e o Brasil já alguns anos que se encontram à beira de uma hiper- inflação (que no caso da Argentina parece estar afastada momentaneamente), ou será que não?

Esses eventos geraram problemas econômicos, contábeis e políticos sérios. Os diversos países, cada um a seu modo, procuraram resolver esses problemas. Do ponto de vista contábil, vários ajustamentos foram propostos, seja usando-se a contabilidade a Nível Geral de Preços, seja usando-se a metodologia do Custo Corrente para dizimar as mazelas que a inflação e as variações de preços específicos provocam na Contabilidade e no resultado das organizações.

Nos Estados Unidos da América, que foram acossados por uma inflação elevada para os padrões americanos que chegou quase ao patamar de $20 \%$ a.a. nos anos 70 , chegou-se a utilizar em informações adicionais às elaboradas com base no custo histórico, entre 1979 e 1984, a metodologia do Custo Histórico Corrigido combinado com o uso por algumas empresas de grande porte da metodologia do Custo Corrente, conforme preconizado pelo FASB 33. Entretanto, este foi derrogado em 1984 e, presentemente, as empresas americanas deram um passo atrás, passando a usar de novo apenas a metodologia do Custo Histórico. A Inglaterra e os Países da Comunidade Britânica, por influência dos Estados Unidos, usaram por alguns anos o Custo Corrente na contabilização dos eventos contábeis, porém após o retrocesso americano, também voltaram ao Custo Histórico.

No Brasil, no Chile e em outros países da América Latina utiliza-se a metodologia do "Custo Histórico Corrigido" (conhecida no Brasil por Correção Integral), total ou parcialmente.

Quanto à Correção Integral utilizada no Brasil e que cobre somente as empresas abertas notamos que sua utilização representa um grande avanço de informação, porem alguns ajustes ainda se fazem necessários para que a informação seja de melhor nível. Esses ajustes dizem respeito à correção na formação dos estoques, bem como trazer a valor presente todos os valores a receber e a pagar.

\section{CONSIDERACÕES FINAIS}

O estuário natural para onde convergem as teorias de avaliação de Ativos é a demonstração e a quantificação satisfatória dos potenciais de serviços que esses ativos

Caderno de Estudos no06, São Paulo, FIPECAFI, Outubro/1992 
Avaliação Patrimonial em Contabilidade á Valores de Entrada e Saída 11

apresentam para a entidade.

De forma significativa cada teoria que foi explicitada, com suas virtudes e limitações, persegue esse objetivo. $\mathrm{O}$ arcabouço teórico e a forma metodológica que cada uma delas traz em seu bojo pode ser alvo de críticas, mas sem dúvida contribui decisivamente para a evolução da Contabilidade, de forma a que esta atinja seu objetivo primordial: fornecer informações econômicas relevantes para que cada usuário possa tomar suas decisões e realizar suas avaliações e seus julgamentos com segurança.

De uma forma simplificada pode-se classificar os usuários em dois grupos; 0 Público Interno e o Público Externo. Ambos os grupos de "per si" possuem funções a maximizar distintas. Definidos os grupos de usuários julga -se pertinente situá-los em função das principais categorias de ativos e a situação a elas correlacionadas. Tais colocações estão demonstradas na Tabela 1, adaptada de Staubus, com observações sobre os critérios utilizados pela Lei 6404/76. Esta tabela representa a posição do autor do presente artigo sobra as melhores alternativas em situações específicas das diversas categorias do ativo. Uma análise acurada da tabela indica uma supremacia da avaliação a valores de saída quando se considera o público interno. Para efeito de usuários externos, talvez a visão de conjunto dos ativos, a objetividade e o julgamento sobre os futuros fluxos da caixa fazem com que se incline eqüitativamente pelos valores de entrada e de saída. Todavia a contabilidade oficial (Lei 6404/76), para nosso desânimo, adota metodologia conservadora baseada em custos históricos e históricos corrigidos.

No intuito de obter-se uma teoria de avaliação mais próxima do objetivo fundamental da Contabilidade, baseada na visão panorâmica da entidade, elaborou-se a Tabela II, inspirada em Largay e Livingstone, com pequenas adaptações. Essa tabela, que reflete a posição a valores de entrada, demonstra claramente o custo corrente corrigido como o mais significativo, embora não seja tão objetivo como querem os contadores. Um painel de avaliação a Valores de Saída pode ser visto na Tabela III. Esta revela que o Valor Realizável Liquido poderia ser perfeitamente identificado como o melhor valor de saída, pois sua única deficiência aparente é a auditoria dos dados. 
Avaliação Patrimonial em Contabilidade á Valores de Entrada e Saída 12

IADERA I

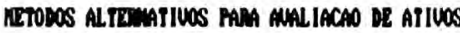

FCR A SINACOES ESPEIFICAS

\begin{tabular}{|c|c|c|c|}
\hline \multirow[b]{2}{*}{ CArDcosin no arino } & \multicolumn{2}{|c|}{ SITUACAO M DSCISAG } & \multirow[b]{2}{*}{$1516.402 / 75$} \\
\hline & FuLICO InTEew & 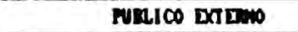 & \\
\hline $\begin{array}{l}\text { a) Direitos e titules de Credito } \\
\text { (Atives Monetarios) }\end{array}$ & $\begin{array}{l}\text { (Pl anejanento e Controle de Lisuider) } \\
\text { - Musen de Caixa hescontado }\end{array}$ & - Flusoo de Caixa bescontado & $\begin{array}{l}\text { Valor original mais rendimentos } \\
\text { ou Valor de Mercado se este for } \\
\text { menor. }\end{array}$ \\
\hline $\begin{array}{l}\text { b) Vens Mantidos para Venda } \\
\text { Uendas Mormais } \\
\text { Vendas Criticas }\end{array}$ & $\begin{array}{l}\text { (Avaliacao de Desenpento) } \\
\text { - Valor Mealix. Limido } \\
\text { - custo de Reposicas }\end{array}$ & $\begin{array}{l}\text { - Valor Realiz. Liquido } \\
\text { - Custo de Reposicao }\end{array}$ & $\begin{array}{l}\text { Custo de aquisicao ou producao, } \\
\text { deduzido de provisao para ajusta-1o } \\
\text { ao valor de Mercado quando este } \\
\text { for inferior. }\end{array}$ \\
\hline c) Kens Mantidos rara Uso & $\begin{array}{l}\text { (Pl anejameato controle e mali iacao } \\
\text { \&e desenpentro) } \\
\text { - custo de heposicas }\end{array}$ & - Custe de Reposicae. & \\
\hline (1) hicoes Megociadas & $\begin{array}{l}\text { (Pl anejamento e Controle de liquidez) } \\
\text { - Valor Realiz. Li quido }\end{array}$ & - Valor Realiz. Liquido & Custo ou mercado dos dois o menor \\
\hline
\end{tabular}

Caderno de Estudos n06, São Paulo, FIPECAFI, Outubro/1992 
IABELA 1

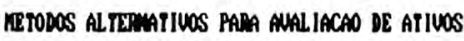
PACE A SITUACOES ESPECIFICAS

\begin{tabular}{|c|c|c|c|}
\hline \multirow[b]{2}{*}{ Cardconin No ATINO } & \multicolumn{2}{|c|}{ SITUACAO MA ASCISAO } & \multirow[b]{2}{*}{ LE1 6.49475} \\
\hline & whics imewo & PURICO DTIDew & \\
\hline $\begin{array}{l}\text { e) Ativos, Permanentes } \\
\text { (Valores que noraalmente nad sao } \\
\text { utilizados no objetivo social da } \\
\text { empresa) aao avaliados pela equi } \\
\text { valencia patrimonial }\end{array}$ & $\begin{array}{l}\text { (Plane jamento e Controle de Liqui dex) } \\
\text { - Valor Realiz. Liquido }\end{array}$ & - Ualor Realiz. Liquido & $\begin{array}{l}\text { Custo de Aquisicao, deduzido de } \\
\text { provisao de perdas provaveis na } \\
\text { realizacao de seu valor, quando } \\
\text { cokprovada }\end{array}$ \\
\hline i) Ativos Mpreciaveis & 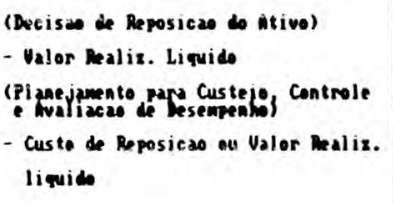 & - Custo de Merosicao & $\begin{array}{l}\text { Custo de Aquisicao Corrigido } \\
\text { excluido da Depreciacao Acumalada }\end{array}$ \\
\hline $\begin{array}{l}\text { g) Altivo Diferido } \\
\text { (Intangiveis) }\end{array}$ & $\begin{array}{l}\text { (Pl anejamento e Coatrole) } \\
\text { - Custo Corrente (se possivel) oce } \\
\text { Custo Mist. Corrigido. }\end{array}$ & $\begin{array}{l}\text { - Custo Corrente cu } \\
\text { - Custo Nistorico Corrigido }\end{array}$ & $\begin{array}{l}\text { Gastos Aplicados excluidos das } \\
\text { amortizacoes comigidas }\end{array}$ \\
\hline
\end{tabular}


Avaliação Patrimonial em Contabilidade á Valores de Entrada e Saída 14

TARQA II

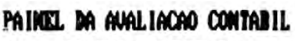

VALORES DE EATMABA

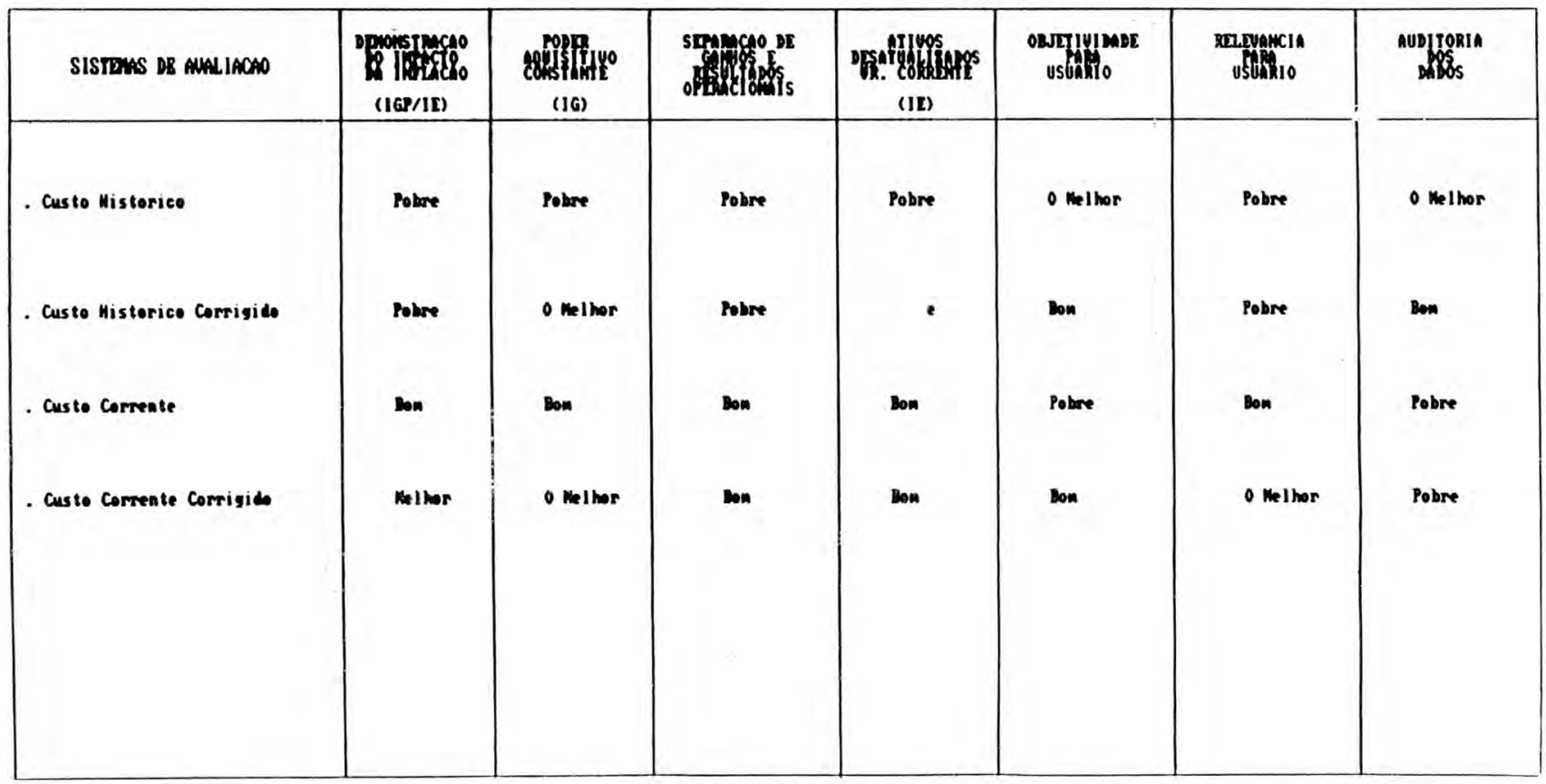


IANA III

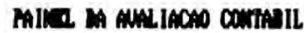
VLLONS DE SAIM

\begin{tabular}{|c|c|c|c|c|c|c|c|}
\hline SISTOAS OS MALIACAOO & 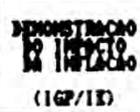 & 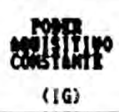 & 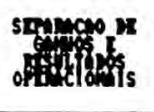 & 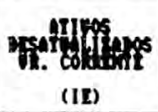 & 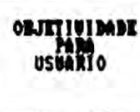 & 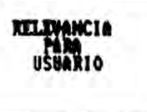 & 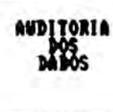 \\
\hline 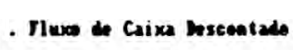 & $m$ & 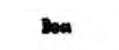 & Polve (4) & Polve & an (1) & Bon & Bon \\
\hline . Valor keal izavel Liegrid & $3 m$ & mon & m (2) & on & mom & Bom & Polire \\
\hline $\begin{array}{l}\text { Ineivalentes cormetes de } \\
\text { Caixa }\end{array}$ & $m$ & $m$ & $\ln (2)$ & mon & nom & Polire (3) & Polive \\
\hline
\end{tabular}

1) Se definidas sass eres variaveis basieas.

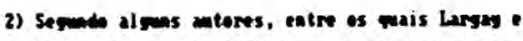
Liviogstene, tal atributo e rrivative do custo correate do custo cerrente corrigibs.
3) Meadribsen observa, inclusive, we a falta de medicoes - a waier falla do equivalente corrente de caixa.

4) Posicas defendida por Patrick Xirbona.

\section{BIBLIOGRAFIA}

CHAMBERS R.J - Accounting Evaluation and Econimic Behavior; Englewwood Chiffs, N.J: Prentice Hall, inc. 1965

EDWARDS. EDGARD O. E PHILIP W BELL - The Theory and Measurement of Business Income - Berkeley and Los

Angeles: University of California Press, 1961

HENDRIKSEN. ELDON - Accounting Theory - Homewwood Richard D. Irwin 1970 e 1977

IUDÍCIBUS. SERGIO DE - Teoria da Contabilidade, Atlas, 1981

LARGAY. A.JAMES e LIVINGSTONE JOHN LESLIE - Accounting for Changing Prices, John Wiley \& Sons, mc. 1976

MARTINS. ELISEU - Contribuição à Avaliação do Ativo Intangivel:- Tese de Doutorado, FEA-USP 1972

MOST. KENNETH 5. - Accounting Theory; Grid Publishing inc., Second Edition 1982

PEDROSA. CARLOS JR. e TINOCO, JOÃO E.P. - Avaliação Patrimonial em Contabilidade a Caderno de Estudos nº6, São Paulo, FIPECAFI, Outubro/1992 
Avaliação Patrimonial em Contabilidade á Valores de Entrada e Saída 16

Valores de Entrada e de

Saída - trabalho não publicado, apresentado na cadeira de Teoria da Avaliação Patrimonial FEA/USP, em 1985

KAM, VERNON - Accounting Theory - John Wiley \& Sons, 1986, New York

KIRKMAN. PATRICK R.A. - Accountinq Under Inflationary Condition - George Allen e Urwin Ltd., London 1978

SCHMALENBACH. EUGEN - Le Bilan Dynamique - Edição de 1961, DUNOD, Paris

STAUBUSGEORGE J. - Alternativa Asset Flow Concepts -Accounting Review, Vol. XLI - Junho 1966

SWEENEY H.W. - Stabilized Accounting; Holt, Rinehart and Winston Ind., Copyright 1936, edição de 1964 